\title{
Egypt: Economic Pressures after Two Years of Revolution
}

\author{
Ibrahim Mosad Elatroush ${ }^{*}$
}

Department of Economics, Tanta University, Egypt 


\title{
Egypt: Economic Pressures after Two Years of Revolution
}

\author{
Ibrahim Mosad Elatroush ${ }^{*}$ \\ Department of Economics, Tanta University, Egypt
}

\begin{abstract}
This paper focuses on the impacts of the transitional period on the Egyptian economy after $25^{\text {th }}$ of January revolution. It covers gains, loses, and challenges that face the Egyptian economy; what is achieved and what is needed to be achieved in order to avoid bad scenarios? Results recommend short term or urgent actions to be fulfilled en route for putting the economy on track.
\end{abstract}

Keywords: Transitional period, revolution, Egyptian economy, challenges.

Jel: E20, D70, 130.

\footnotetext{
* Department of Economics, Tanta University; Faculty of commerce, Said Street, Tanta, Egypt. Phone: (002) 0112- 000- 6400, (002) 040-331-6586.

Email:ibraelatroush@ hotmail.com
} 


\section{Introduction}

Mubarak's regime had a notable stability over thirty years. On $11^{\text {th }}$ of February 2011, after eighteen days of massive protests, Mubarak was forced to step down. While the revolution of January $25^{\text {th }}$ led to a major success, the fall of Mubarak, Egypt's political future is still vague and exposed to a number of risks. This paper evaluates the outlooks of the transitional period in Egypt, by looking at the main political, socio-economic, and economic challenges facing the country.

In1981Mubarak became a president after Sadat's assassination. After a period of relative tolerance in the 1980s, Mubarak's dictatorial rule deepened in the 1990s: civil and political rights were restricted; the parties' law was amended; press freedom was significantly limited and suppression was used against political opponents, particularly the Muslim Brotherhood (MB) and other Muslims groups. These restrictions and widespread interference in the electoral process through fraud, domination and intimidation, especially the parliamentary elections 2010, are considered as chief factors behind emerging the revolution.

The Egyptian economy is suffering from the impacts of the transitional period. While the shift from dictatorship is definitely desired, it has certainly triggered instability unknown to Egypt for the past thirty years. The implementation of economic reform within this uncertainty is particularly challenging as political demands take priority. Successive, though unsuccessful, reform programs during the 1990s contributed to poverty widespread that served as a principal driver of the 2011 revolution and persists up to now. Past experiences can provide useful lessons for what to avoid in the future, even if they are unable to reveal exactly what should be done.

A successful transition to democracy can be facilitated by a sound economy and the economic well-being of citizens.

\section{Economy's outlook since 2011}

The Egyptian economy has been performed poorly since 25 January 2011; rate of growth has fallen by almost 4\%. Revenue from tourism has collapsed in 2011 then it has started to recover partly in 2012 in Red Sea cities but still very weak in Cairo, Luxor, and Aswan putting pressures on the balance of payments and then foreign reserves. Official reserves have fallen by $\$ 23$ billion during the supreme council of the armed forces (SCAF) era (February 2011: June 2012). Egypt also faces an 
external financing gap of about $\$ 12$ billion in the second half of 2011 and the first half of 2012. Figures $(1 \& 2)(5 \& 6)$ and $(7 \& 8)$ in the appendix depicts changes in the rate of growth, Tourism revenues, and International reserves respectively.

Moreover, the transitional government has encountered pressures because of populist demands and abandoned or a new case of irrational media that amplified the populist demands and their consequences led the government to: First, it tolerated allegations of corruption and exaggerated figures to be spread in the media without response. With such allegations, many businessmen fear the risk of nationalization because economic liberalization is being equated with corruption.

Second, the transitional government is inflating the budget to appease the demands of the protesters. It has offered fixed contracts to 450,000 temporary employees and approved a $15 \%$ public-sector wage increases that will raise the total pension expenditure in 2011 afterwards fixed contracts are raised to 700,000 fixed contracts by the end of 2012. Together, these actions increase the state's total wage and pension bill by $72 \%$ in 2013 /2014 budget draft. The consequences of the sharp increment in fixed contracts affect negatively on the unemployment rates by raising them as in figures $(15 \& 16)$

Additionally, the minimum wage for public employees has been increased from 400 Egyptian pounds to 700 Egyptian pounds in 2012 and then rose to 1200 Egyptian pounds in 2013. While creating jobs and raising salaries are important to protect the rights of workers, this reactive cycle of demand and commitment create more pressures on the budget and lead to raise the budget deficit.

Since spending exceeds revenues, the state will cover this deficit from either domestic or foreign sources and this deficit was 135 billion Egyptian pounds according to fiscal 2013 draft budget prepared by the Ministry of Finance. In the absence of a parliament, SCAF approved the budget. Until recently, the majority of the governmental borrowing has been from the domestic market. Domestic debt in 2011 registered an increase of $19.6 \%$ over 2010 in absolute figures and $1.7 \%$ relative to GDP. External debt increased by $6.9 \%$, while its share to GDP has declined because GDP growth surpassed the growth of debt over the same period. Borrowing from the domestic market at higher rates than in the international market creates an additional burden on the budget and increases the crowding out effect. Thus, high lending rates combined with other several restrictions during this critical time of 
transition affect liquidity and hinder investment. According to these recent developments, four possible scenarios could emerge during this period. These scenarios will rely on the transitional government's actions:

1. Satisfying the demands of the street in a repeated and reactive manner will continue, and the budget deficit will rise to increasingly unsustainable levels. If this occurs, economic performance in key sectors will continue to decline and security will deteriorate, increasing unemployment, poverty, and then the country's instability.

2. Attract some funds, but the government will continue to reply to street demands by increasing public expenses without confronting structural and institutional challenges. Under this scenario, the economy will continue subjected to uncontrollable level of public outlay and unchanged economic system that lead to a slow shift to democracy. 3. A logical macro context is outlined which is laid to deal with immediate demands and to look ahead to possibilities that will address medium term challenges. Under this scenario, the confidence of banks in the transitional period and the government would be strengthened gradually consequently political stability will be rebuilt.

4. Economic performance improves owing to the success of the government to recoup security and stability without implementing a consistent framework or coordinated action. This scenario would renew private sector investment activity, and the economy would recover. However, lacking a clear framework, a hindrance would surely occur and the situation would deteriorate. While the fourth scenario denotes the best possible option from the view of the transitional government, it is unlikely to happen.

Unfortunately, during the period of the SCAF which ended on 29 June 2012, the first scenario is done due to some factors among them; strikes and road blocking became a regular phenomenon, irrational elites who are looking for their narrow gains, demands for higher salaries for all sorts of employees whether their salaries are low or acceptable besides the side effects of obstructing roads and regular Friday protests with different names and reasons. This led Egypt to achieve a World rank in the number of protests. All mentioned factors led to worsen the budget deficit due to the increase in wages, a sharp decline in tourism from 14.7 million tourists in 2010 to 9.8 million in 2011, an increase in subsides along with a sharp deficit in net exports which led to a severe decline in foreign reserves from \$36 billion in January 2011 to $\$ 16.4$ billion in January 2012. 
None of the scenarios is exclusive; the outcome will most likely be a combination of the second and third scenarios. Addressing the economy today with a combination of short and medium term solutions can do a best comprehensive reform.

\section{Research Methodology}

This paper methodology is based upon two parallel ways; firstly it will cover two different historical periods after Mubarak's stepped down; the first era covers the period where SCAF managed the country (eighteen months) and the second when the president Morsi rose to power on 30 June 2012. Secondly; we will cover the economic pressures, which faced the Egyptian economy during the two periods. What is done to fulfill revolution's aims, and what is needed to do to overcome the drawbacks of the transitional period in both short and medium period to mitigate its negative impacts and put the economy on track.

The SCAF who received the responsibility of managing the country until the parliamentary and presidential elections are held faced tremendous challenges. Its period witnessed unwisely hasty to fulfill majority's demands of the revolution with little respect to their long-term effects. For instance, the government raised public sector employees' minimum wage alongside shifting 450,000 workers from temporary contracts to fixed contracts, which led to more pressure on unsustainable budget deficit together with the chronic inefficient subsidies, and the implications of continuous poor economic policymaking.

Because of the instability inherent in transitioning countries, the Egyptian economy witnessed decay from February 2011and it was intensified due to the global downturn. This sort of economy slowdown is clearly seen in terms of domestic consumption, direct private investment, and tourism.

In order to achieve the aims of the paper, there is a need to shift the economy onward. Thus, the transitional government must prioritize the short run and medium term procedures. In this regard, there is a need to have a quick glance on these procedures to examine what is achieved during the past two years and what is needed to fulfill.

\section{Short run programs}

- Rebuild reservations 
- Draw a clear strategy for public sector's modernization

-Rebuild trust between the government and the private sector and encourage entrepreneurs' partnerships

- Adopt a transparent approach in the decision making process

- Guarantee more funds for small and medium enterprises

- Redirect notable amount of foreign grants and ease loans for infrastructure, public utilities and housing projects to the poor

\section{Medium Term Programs}

In the medium term, which will launch after the parliamentary elections, the government is in need to:

- Strengthen weak institutions

-Deepen thoughts and proposed creative solutions for the dilemma of low investments and limited financial resources

- Correct market failures (the relationship between producers and consumers)

- Set policies which overcome negative effects of growth that widen the gap between the rich and the poor

Addressing these problems alongside applying the mentioned short and mediumterm procedures is a prerequisite to put the economy back on track and avoid any more expansions of public outlay to even further unsustainable levels. Until now, the government has failed to follow the right way and has not given proper attention to the economic aspects of the transition. Although there are few improvements, Egypt still has poor governance indicators such as the rule of law, quality of business regulations, and corruption associated with ineffective social spending. The result of these poor scores is inefficient allocation of resources. Without immediate response, the government might face a bad scenario of continuous economic drop.

\section{Short run Programs}

The main challenge facing Egypt is how to initiate short run policies that can converse the economic depression without worsening future economic reform based on a more inclusive economic program. Short run reactions will satisfy some of the street hopes while placing grounds for a healthy economic future. Investment, institutional and governance policies, and social policy issues are the main areas that must be undertaken in the short run. 


\section{Investment}

To attract new investments and enlarge existing ones, three key issues should be done

\section{a. Remove private sector anxieties concerning its investments}

In its concerns to recommence growth, the transitional government has to send a reassurance message to the private sector that their interests and investments are secured. The main reason behind these feelings of worry of the private sector is due to coping with a hostile environment. This has resulted from some corrupted businessmen in the former regime. A noticed risk of nationalization is depressing both domestic and foreign investors and these sorts of fear are highly created during the SCAF era. Although this sound of fear is mitigated through messages sent by Kandil government and several settlements are done with businessmen to improve investment environment, there is still a need for more efforts to remove investors' anxiety about investing in Egypt. Additional factors such as strict and bureaucratic regulations and high transaction costs are also hindering investment and in need to be facilitated. Despite several efforts made in this regard, but it is not satisfactory. There is also a great concern that the transitional government should engage and deal with small, medium, and large-scale enterprises fairly since Mubarak regime disregarded the major role that can be played by small and medium firms (SMEs) in development.

\section{b. More funding facilitation for SMEs via eliminating crowding out}

To date, the government still borrowing from the domestic market at higher interest rates $(13 \%$ on average) relative to international markets. Even if it is unjustified from economic scene, the SCAF members try to avoid external borrowing for political sensitivities and their justification is that they do not want to give an impression that they follow the old regime's policies through further external debt. This led to a sharp increase in domestic debt to be $60 \%$ of GDP whereas external debt still in the safe limits which represents $15 \%$ of GDP. This approach has two bad effects: the crowding out effect that has a bad impact on SMEs, and it burdens the budget with future obligations. The transitional government should either avoid borrowing except for necessity needs or borrowing from the international market to avoid squeezing liquidity and to take the advantage of low interest rates in the external market and that is what Kandil's government starts to follow by obtaining \$8 billion from Qatar, \$2 billion from Turkey, $\$ 2$ billion from Libya, and dealing with IMF for $\$ 4.8$ billion loan but these sort of negotiations will take ${ }_{8}$ time to apply some structural reforms 
among them maintaining the budget deficit.

Additionally, the government can provide incentives via easy funds for SMEs and venture capital based on transparent rules. Similar initiatives failed previously to achieve intended targets owing to bureaucratic actions and corruption. The Egyptian General Authority for Investment and Free Zones stated that SMEs represent $80 \%$ of Egypt's domestic economy and absorb around $75 \%$ of the private sector labor force. Although they have a significant contribution to the economy, SMEs receive only $10 \%$ of available finance, which is considered to be one of the main obstacles to increase their productivity and output. One of the factors that impede their access to finance is the absence of a clear definition of SMEs by the Central Bank of Egypt. Therefore, commercial banks do not use precise criteria of classifying them. The majority of Egyptian banks deal with SMEs as small corporate clients and have no specialized guidelines set for them. Moreover, there is no accurate information about the SMEs. These drawbacks constraint banks ability to adjust their products to SMEs market needs. An efficient way to address such challenges is to set a united standard of collecting continuously updated information with the merit of eliminating data errors.

\section{c. Simplifying regulations to engage the informal sector}

Rigorous regulations that hinder attracting new investments and discouraging business initiatives are in need to be facilitated. For instance, running a business in Egypt takes six steps, seven days, and a cost equivalent to $6.3 \%$ of per capita income. Therefore, these regulations must be simplified. By the way, the government starts to follow what is called "one window procedures" which means that the six steps of running a business will be combined in one place and in one day. Moreover, exiting from the market in Egypt is still more complicated and costly relative to other countries. Thus, there is an urgent need to facilitate doing business procedures. Furthermore, switching to electronic business registration is desired to save time. New laws regulating insolvency and bankruptcy should be activated to help businesses facing financial difficulties.

Despite the informal sector represents nearly $40 \%$ of the economy, it still operates illegally because the business environment is still poor. Improving the business environment would encourage those who work in the informal economy to register their businesses and enjoy the benefits of formality. The government starts to follow 
serious efforts to join the informal sector with the formal one through incentives such as tax exemption for the period before registration and this would widen the tax base and potentially enhance government revenues. This also will be beneficial for workers in this sector since they suffer from poor working conditions, no insurance cover, highly exposed to market changes, and did not receive governmental benefits.

\section{Institutional and Governance Policies}

The distrust relationship between the Egyptian people and formal institutions has a bad historical inheritance. Thus, rebuilding a trust between people and institutions is a prerequisite to maintain the social unity that characterized the revolution besides it will maintain the country's long-run macroeconomic stability.

\section{a. Community's role in decision-making process}

There is an urgent need to engage emerging players; civil society organizations, various political parties, youth organizations, and the business community with the transitional government in the decision making process. Furthermore, the business community should be part of a decision making process at this early stage owing to its vital role in investment.

This can be done through encouraging open debate about important and sensitive issues such as supervision and evaluation of the public spending and official subsidies. This sort of open debates can facilitate change. Unfortunately, the transitional government has avoided this path and the SCAF made its decision to arbitrarily alter expenditures in the fiscal 2012 budget.

Generally, the roles of new and emerging actors are still vague. The SCAF seeks to protect its interests even after returning to the barracks; the military manages around $10 \%$ to $15 \%$ of the economy in areas outside the military scope. Moreover, SCAF members have been distancing themselves from the public arena and have the intention to "lead from behind."

President Morsi tries several times, and still, to gather all community parties in decision-making process but he has faced a severe opposition from the remains of Mubarak's regime and the elites who have a different ideology from MB and they deal with him as member in MB not as a president. In this regard, more efforts should be made from the presidency institution, the government, and other parties to gather their different points of view for the advantage of Egypt. 


\section{b. Law Enforcement}

The SCAF management of the transitional period deepens the widespread belief that corruption exists everywhere. Previous policies in Mubarak era and their implementation, particularly those about economic liberalization, lacked the transparency necessary to prevent the corruption that is still spread widely in Egypt until today. There is no doubt that Egypt under Mubarak leadership was indeed plagued by corruption, and several criminal cases being brought to court deserve appropriate action. Exaggeration on these cases creates an impression that tackling corruption would solve Egypt's economic problems. Ignoring the fact that what economic problems require is economic reform.

More transparent procedures and inspection on public spending would help to ease allegations of corruption and redirect focus to more urgent issues. Information sharing and a more clear budget preparation process would help to work out a new approach towards healthy economic governance in the transitional period. Information spread would instantly contribute to creating a new image for Egypt by sending the right message to revolutionaries and allowing the transitional government to tackle other important issues.

Despite the preparation for the fiscal 2012/ 2013 budget failed to adopt such a process which left Egyptians and investors with the impression that when it comes to the budget, it's business as usual. However, the discussion of the fiscal 2013/2014budget draft at Shura Council witnessed a transparent dialogue that led to impose several amendments on it. The government is in need to enforce laws properly through swift actions, and also requires independent judicial system.

Generally, much more can be done at the institutional level without costing the government additional spending. But if ambiguity and hesitance are still dominant, the desired goals of the short run will be much more challenging to accomplish.

\section{Social Policies}

\section{a. Serious discussions on subsidy dilemma and how to direct it towards targeted groups}

Social spending is considered an important way for the government to cover the gap between socioeconomic groups. Subsidies as a portion of this spending represent $27 \%$ of total spending and 9\% of GDP (2012/2013 budget). The national subsidy program urgently needs restructuring. Total social spending can reasonably be 
sustained during the transitional period through targeting the poor rather than benefiting higher class as the government presently does. The transitional government should begin this restructuring process by sharing information on the distributional effect of subsidies based on income level. (Figures $24 \& 25$ show a sharp increase in subsidies that deepen the budget deficit).

There is an urgent need to distinguish between food subsidy, which is highly sensitive and represents only $16 \%$ of the total subsides, and fuel subsidies, which are mostly consumed by groups not intended to benefit from them and represent $65 \%$ of total subsides. Restricting fuel subsidies would be less sensitive politically but would represent around $20 \%$ saving on total state spending.

In this regard, the transitional government starts to follow a subsidy reform program through distributing the fuel coupons to rationalize fuel consumption and to eliminate the fuel black market. Thus, efficient use of subsidies will help to dedicate it to the targeted groups and spend saved money on education and health sectors.

\section{b. Cohesion between the government and private sector}

Coordination between the transitional government and the private sector is required to unite their efforts on social policies. The private sector has several initiatives to bear its social responsibility and is in need to undertake coordinated efforts in an attempt to improve his bad reputation. The government can, for instance, revive preceding initiatives such as the " 1,000 poor villages" This initiative, launched in 2007, aims to improve the status of 1,000 villages through improving the infrastructure of basic education, fight illiteracy, offer more jobs, and other services. These villages were chosen according to a poverty reduction plan through the Egyptian Ministry of Economic Development and the World Bank. The initiative, which cost more than $\$ 700$ million in its first phase, has carried out about 1,400 projects so far. The private sector should be encouraged to participate in this and other initiatives to remove its bad inherent since most of the Egyptian private sector contributions to social activities and charity works are negligible relative to what is done in Europe and America. Moreover, this would offer fund for some public resources that the transitional government could allocate to education and health.

\section{c. Strengthen social dialogue}

The transitional government failed to launch a method to a social dialogue to avoid 
resorting to strikes or violence. Dialogue among various categories would establish a sense of decision making as a long run process, a possibility that was distorted in the past because of political oppression and the weakening of social institutions and labor unions. Comprehensive dialogue including all parties would also comfort private investors who want to avoid any surprises during the government transition. Unfortunately, both the government and the opposition have failed to compromise about any point or build a successful dialogue. Up to now, the opposition did not have any vision or ideology about the country's issues or how to pass the transitional period besides it has a little widespread among people. Its power is only obvious in talk shows programs or at media and this leads the people to say that the main goal of the Egyptian elites is just " critics for critics". Thus, both parties need to set together and give the priority to make the country advantages overhead any private gains.

\section{d. Give more attention to education and health}

The transitional government should set strategies to tackle weakness in these vital sectors and improve the quality of services. This would require some financial resources that might not be available in the short run. New tools to evaluate performance and reallocate resources would be a welcome change from the practice of the previous government, which fundamentally ignored such critical issues. Although Egypt suffers an insolvency problem like any country faced transitional period, the government and the presidency give more attention to education and health as a prerequisite for increasing productivity and welfare. The government raises the allowances for education and health in 2012 / 2013 budget to $17 \%$ of total spending and it expected to increase by $20 \%$ in 2013 / 2014 budget draft.

\section{Post-Election Programs}

Medium period programs will launch after the parliamentary elections are held. Number of objectives needed to be achieved by the elected government. These objectives should comply with the demands of both the protesters and the people. Thus, the future government should give more attention to:

- Reduce poverty and boost rates of growth

- Control Unemployment via creating more jobs

- Implement policies aim at income redistribution in a proper way

- Enhance investment through more incentives 
- Improve infrastructure and services

- Minimize the budget deficit and enforce the rule of law

- Modernize and improve the education and health

- Set social policies focus on intended groups

To achieve the required goals, the elected government must face substantial challenges and decide how to:

- Overcome the low levels of investments and limited financial resources

- Productivity enhancement for economy as a whole

- Raise the governance score and reinforce institutional framework

- Apply efficient social policies

The procedures that the government and the private sector follow to overcome such obstacles will affect not only economic growth but also progress towards democracy.

\section{Lack of Investment.}

\section{a. Promote the partnership between private and public sectors}

Egyptian economy is suffering from the lack of investments. The minister of finance declared that the gap between savings and investment is huge where local savings cover from $55 \%$ to $60 \%$ of the annual targeted investments. Therefore, the government necessities are to increase the level of investment financed by domestic private investors who have been still hesitant since the revolution or from foreign direct investment (FDI). If this sort of hesitancy continues, the effects on the economy will be harmful and will open the way to the scenario of an unsustainable budget deficit and a return to dictatorial rule.

To prevent this situation, the government should do its best via providing incentives to attract private investments. This entails to offer a friendly business environment, a consistent political framework, and a stable political environment. Encouraging partnership between the public and the private sectors in different fields especially in infrastructure is required. Both the private sector and the banking sector have financial and technical resources to adopt such projects, but without appropriate regulations these initiatives will be ineffective.

Additionally, a partnership between the public and the private sector in manufacturing areas is also desired since the public firms are benefiting from the advantages of locations, buildings, human resources, cheap raw materials, economies 
of scale, and workers whereas they are suffering from obsoleted equipment due to a lack of finance. Thus, it is better for the private sector to utilize public firms' capabilities through injecting investments in equipment modernization rather than setting up new factories that cost a lot of money in buildings and infrastructures.

Another source of potential investment is FDI, which is expected to increase if Egypt's security situation improves and an elected government announces a clear plans and strategies. (Figures 9 \& 10 show a sharp decline in FDI after the revolution). This transitional government tries to pursue funding from the African Development Bank and some Gulf Cooperation Council countries. Kandil government starts to negotiate with the IMF for a $\$ 4.8$ billion loan. Also, regional development agencies are increasingly playing a prominent role in setting the development agenda for the region and this needs more efforts from the government to cooperate with such agencies.

Low investment levels through domestic sources are also contributing to Egypt's current economic problems. The level of domestic savings to GDP is averaged from $16 \%$ to $18 \%$ of the GDP whereas the needed annual investment for development should be at least $30 \%$. This level of investment is considered low relative to other countries. For instance, the average in the BRICS economies (Brazil, Russia, India, China, and South Africa) is around 27\%, and in emerging Asian countries it is even higher. Low saving levels reflects a low ratio of investment to GDP relative to other emerging economies.

This sort of low level of investments reflects a sort of governmental failure in marketing for investments or giving attention to specific sectors. This has resulted in concentrating investment in "secured sectors" such as construction and financing trade rather than diversify resources to manufacturing or more dynamic, innovative sectors. The manufacturing sector's share in Egyptian economy, for instance, has been declined since the early 1990s. When measured by the volume of manufacturing value added to GDP, emerging economies performed better than Egyptian economy, particularly since 2000. The gap between these countries and Egypt has been extending, which indicates that development goals cannot be achieved by focusing only on one sector (services) performance. While industrial contribution to the BRICS and Asian countries increased over the past decade, it declined in Egypt. This is not surprising if we consider the combination of low level of investments, the nature of 
elites business in Egypt, and the political stability \& corruption indicators that hinder investment. (Figures $28 \& 29$ display the contribution of economic sectors to GDP)

Obviously, investment levels must increase at least similar to emerging economies if the government wants to diversify its economic resources and create more jobs.

\section{b. Promote comprehensive growth}

There no doubt that the rate of growth depends on injected investments. However, one has to be careful that growth is not enough for distributional objectives. Focusing on some indicators such as a progressive tax system and improving education to increase access of the poor to job market can address welfare concerns. Comprehensive growth should be related to a more fair distribution of resources. It also has to create new jobs and contribute to a diversified economy. New jobs are also expected to reduce poverty and enhance livelihood. Since Egypt has a higher unemployment rates then labor-intensive technique is a proper one to absorb unemployment, the post election government should focus on enhancing productivity in the agricultural sector. Egypt has a considerable rural population (\%58 of the total population), and the agricultural sector employs large numbers of workers. Thus, introducing new technologies and improving farmers' skills through targeted training programs can increase agricultural productivity. Farmers complain about the lack of funds, access to the market, and huge barriers created by traders. In this regard, the president Morsi and the government pay attention to farmers via cancelling their banking debts and encouraging them to plant strategic crops such as wheat, corn, rice, cotton etc. The government guarantees an advanced price exceeds the World prices plus a guarantee of receiving the crops directly from farmers. These incentives encourage farmers to increase the planted areas and productivity.

Moreover, microfinance could be utilized as one of the devices to promote growth. A successful example is the Misr El Kheer Economic Livelihoods Program, which offers easy loans to create jobs for women living in the neediest areas. The initiative is built on the premise that local communities can be enabled to handle their own development in a sustainable way. The focus is on the comparative advantage possessed by local communities in the form of producing traditional carpentry, seashell, and other local crafts.

In addition, the post transition government must ensure the provision of adequate health care and education services. Quality of education is particularly 
important for breaking the cycle of poverty by enabling the poor to become qualified for job opportunities in the sectors that require high levels of skills and are well paid. Comprehensive growth is possible with a combination of improved education, stimulated and secured investment, and a welfare system that targets the poor.

\section{c. Market structure development}

The main problem of the Egyptian economy is that its market structure remains highly concentrated, given the prevalence of business elites and their excessively comfortable relationship with bureaucrats under the old regime. Regulations were designed to protect the existing market structure with few producers and traders controlling a major share of the market. Such a market structure ensures high profits, which ultimately abuses poor and middle-class groups. To overcome this dangerous problem, the future government must restructure the existing market and implement mechanisms to ensure fulfillment.

\section{d. Pool informal sector in economy}

The Egyptian informal sector represents $40 \%$ of the economy. Most of the informal entities are small and mainly operated manually. 82\% of Egyptian firms are small and micro firms. The majority of the informal economy is tied to youth projects and more specifically to small and micro firms. However, these entities are limited in their ability to access to finance, and their potential growth is negligible.

Previous regime's laws helped to hinder any potential growth and regulations, which offer no incentive for these firms to join the formal economy. If the intention of the government is to encourage such entities to join the formal sector, it should change the incentive scheme. Therefore, the strategy should be changed. For instance, the government may give a grace period to the already established informal entities before they turn into formal sector. During this period, firms could benefit from financial incentives such as credit facilities and some technical assistance that could help them developing. Creating an agency to collect information and provide advice on how to improve productivity would also be helpful.

In general, reducing informality requires a set of coherent policies that range from fiscal policy to monetary policy. Several measures have to be undertaken in various fields to make this possible. Restricted access to finance is a demanding issue that must be addressed. Less than $4 \%$ of total lending is devoted to small and medium 
firms. Moreover, the taxation system needs to strike a balance between effective revenue generation and the provision of incentives to attract businessmen switch to the formal sector via proportional taxation rates. This leads us to raise an essential question is how to reform the educational system to guarantee graduates who are qualified for the job market. By encouraging graduates today to engage in the formal sector and rely on it to secure jobs and better living conditions, trust and reliance in the benefit of formal channels will be increasingly realized. This will not be a fact in the absence of a clear labor market strategy that offers detailed information about the labor market in both demand and supply sides.

\section{e. Improve wages and productivity alongside flexible labor regulations}

One of acute Egyptian economy problems is a productivity slowdown especially in the public sector entities where labor productivity is too low. Thus, improving productivity is a prerequisite to enhance the Egyptian economy's competiveness. This entails an improvement in labor skills through intensive and modern training programs. More flexible labor laws and regulations from the employers' perspective should be adopted. A flexible labor market also translates into increased competition and productivity. Nevertheless getting a job in Egypt does not necessarily keep workers above the poverty line. Before the revolution, the minimum wage in the public sector was too low. The women participating in the labor force is very low (23\%), this simply means that many workers have been living below the poverty line. Poverty in Egypt persists among workers in all sectors (public, private, and informal).

The percentage of wages (compensation to employees) in Egypt relative to total income has declined, suggesting that registered growth has contributed more to profit and taxes. According to World Bank development indicators, the percentage of wages to GDP has decreased from nearly $8.2 \%$ in 2002 to nearly $7.4 \%$ in 2009 . After the revolution there are a noticeable increment in labor minimum wages that become now around 1000 Egyptian pounds for unskilled private sector worker and around 2800 Egyptian pounds at public sector entities (CAPMAS, 2013).

\section{Institutional Weakness}

\section{a. Stop preferring big businesses and apply the rule of law}

The main characteristic of Mubarak's regime is law disrespect and disregarding judgments. Moreover, two major features characterized the reform process in Egypt 
under the former regime. First, the introduction of laws liberalizing the economy was accompanied by other legislative changes that increased the already dedicated power of government executives. Second, the new laws, amendments, or decrees were not paired with the development of institutional mechanisms for implementation. This deficiency reduced the laws to idealistic statements lacking application. The weakness of enforcing mechanisms was particularly evident in laws of competition, trade liberalization, deregulation, and privatization.

Egypt has poor ranks on governance indicators relative to other emerging markets. It also has low scores of government effectiveness related to the efficiency of governmental institutions and their role in socioeconomic development. This ranking must be enhanced if Egypt wants to proceed with economic reform and achieve its desired goals.

Egypt's forthcoming government should make more efforts to enhance the independence of the judicial system and to build capacity for ways to deal with market laws such as antitrust regulations, protection of consumers, intellectual property rights, anti-dumping laws, and trade policy issues.

\section{b. Labor unions and consumer associations' enhancement}

Unfortunately, Egyptian labor unions and consumer federations are suffering from weakness, dispersion, dependency, and inefficiency relative to advanced countries. Participation by consumer associations, trade and labor unions, and similar institutions were minimal. Sometimes these groups were even silenced through formal legislation. Placing these unions under the supervision of the government led significantly to weaken them and led to labor protests in 2009 and 2010 and facilitated the way for the 2011 revolution. Intervention in general and local elections by the security was also clear and life evidence.

To get balance between producers and consumers and between employers and employees, organizational power to defend the rights of various organized groups (employees) and spread groups (consumers) must be enhanced and strengthened. The misuse of power by elites has weakened the role of civil society and institutions and unions that should become involved with the process of transformation from tyrannical rule. Constant allegations of corruption by a public are lacked confidence in the system. Egypt's newly elected trade unions got on September 2011. The core of the drive begins at the huge Misr Spinning and Weaving Company in the 
industrial city El Mahalla El Kubra that consists of 22,000 textile workers. They are also seeking a tripling of bonuses and state intervention to increase investment, machinery upgrading, and the supply of raw materials.

The post transition environment is expected to resurge by the trade union role, giving unions the power and validity to negotiate their terms with employers and allowing them to build their own power as an emerging group.

Civil society organizations, although maintaining a presence in Egypt for the past few decades, should also grow in power so as to enforce new laws regulating antitrust and market competition. These existing or newly established organizations would contribute to making a balance between producers and consumers. They also can help set a limit on the level of cruel profit in concentrated markets such as cement or steel where a few producers control a large market share and hence control prices.

\section{c. Engage young people in the decision making process}

Several groups who had been excluded during the former regime should be involved in the decision making process. Members of the opposition plus the young revolutionary forces are trying to cooperate so as to build new and transparent institutions and create a new image for the country.

For the economic level, the change is significant: Many previous business tycoons such as Hussein Salem and Ahmed Ezz, who were symbols of crony capitalism and corruption, have been indicted for fraud and wasting public funds. Demolishing the elitist system and implementing transparency measures will give chances to a new generation of entrepreneurs and a new start for the nation's economy. Egypt will become gradually reliant on its youth, who face unemployment and considerable economic hurdles.

Moreover, young businessmen confederations will no longer be limited to the traditional class or to represent relatives of the already established business community. Instead, blue-collar organizations are likely to emerge. Policymakers can expect to face hard questions from those youths who led the revolution.

The private sector should similarly show a new image in this transition and later in the post-election government by following activities through formal, legal channels, and it should commit to corporate social responsibility. It can further pronounce a clear policy on social responsibility in order to change its bad image and show that its interests go beyond profit making. The decision making process in the "new" 
Egypt can and should be more transparent, open, and sharing. Decisions should no longer be limited to elite groups negotiating with weak, complacent bureaucrats, but rather should be an outcome of a collective dialogue process. These kinds of instruments will not work out automatically. It will take time for the young people to identify how to work collectively and what channels can be followed to lobby for their goals.

Therefore, young people are in need to be patient and do not be rush to gain the outcomes. In Chile, South Africa, Romania and Hungry, countries that experienced regime change, the new political and economic order took years to develop. One way of beginning this process is through widening the participation of the public in deciding budget priorities. Currently there are several black boxes in Egypt's budget that the public knows little about. Very few know how the government allocates its public expenditures. A formal institution such as an economic and social council can be created open dialogue regarding such explosive issues with the participation of civil society, media, employers, and employees.

\section{Generous but Ineffective Social Policy}

\section{a. Restructuring social spending and focusing on areas that help the poor}

There is an agreement among Egyptian economists that the current form of subsidies is unsustainable. The government can start with some gradual steps to improve this system and ensure that subsidies are reaching the targeted groups. This would enhance the efficiency of social spending. Moreover, slight changes to subsidy spending could release resources for reform in the education and health. Egypt can benefit from the experiences of other countries that can provide technical assistance.

Certainly, what is being spent on subsidies in Egypt exceeds what is being spent on education and health combined as mentioned earlier. If a new arrange is emerging, the government could be expected to allocate more resources to sectors that would contribute to achieve social justice and equity.

Rationalizing subsidies became vital and by the way Kandil government starts to follow brave steps to restructure the fuel system, which comes into force by August 2013 since this system represents more than 65\% of total subsidies (95billion Egyptian pounds) and the benefit of the poor from this item is negligible.

\section{b. Taxation Should Be Reviewed}


The government needs to rethink about its tax policies, but the subject has gained little attention since the revolution and it has not been broached. Taxation reforms could establish a new relationship between the business community and government based on sharing role for business. Two issues raise in this regard: one related to the potential progressive tax that has been widely avoided in the past, and the second related to the kind of incentives the government can offer to small and medium firms.

The current taxation system is clearly inadequate to reduce the budget deficit. With no tax on capital gains and with corporate and individual tax rates at a maximum of $20 \%$, which is below the global average of $25 \%$ for corporations, and $30 \%$ for individuals therefore revenues will never match spending. In 2012 budget, it is suggested that the higher tax set be raised to $25 \%$ for large corporations and wealthy individuals and that a $10 \%$ capital gains tax has been introduced. Apart from the capital gains tax, the SCAF passed the tax increases. Tax elusion is also a considerable problem in Egypt; it is obvious in the informal sector or other areas that have been neglected in the past.

Fairness requires imposing taxes on all eligible units and should be part of a restructuring plan that aims to expand tax pools while at the same time increasing efficiency in public spending. The Shura council on May 2013 approved a new taxation system that raised the tax for large businesses to be $25 \%$ instead of $20 \%$ and raised the exemption for low-income people from 7 thousand to 12 thousand Egyptian pounds and follow a progressive tax starts from $10 \%$ to $25 \%$. These amendments will take effect in the 2013 / 2014 budget. Moreover, Kandil government offers incentives to the informal sector in order to join the economy and to increase the budget revenues besides reducing the elusion cases.

\section{Conclusions}

The government's ability to establish political and social stability will draw the future of the Egyptian economy. Lots of limitations are present, among them the high expectations and impatience of the public for the behavior of the transitional and postelection governments and the time needed to achieve stability, inadequate resources, and weak institutional power. Coping with expectations without compromising long run stability is the most challenging issue that threatens transition success.

The transitional government has to take serious actions to rebuild the confidence of 
the private sector and removing barriers for new entrepreneurs to purge the slowdown trend in the Egyptian economy. Short run incentives such as production and exports subsidies will be helpful during this time of uncertainty to increase production and create jobs. The banking sector should play a positive role in terms of facilitating SMEs funds.

The Egyptian transitional government has failed to send the right message either about its intentions or management of the economy. It has to carry simple changes that could have remarkable impact on the economy. Morsi's first year of presidency and his transitional government try to do serious reforms to recover the economy. They achieve some of social reforms such as minimum and maximum wages with increasing salaries, farmers supporting, and some improvements in services. But unfortunately, people's expectations are still too high. Thus, they are in need to make more efforts to react to people's hopes.

From one side, there is a great need for serious reforms to fight prevalent bureaucracy, improve efficiency, and resume the role of the state as a catalyst of growth and development. On the other side, the transitional government should make a balance between excessive people's demands and controlling the budget deficit. This is not an easy task and a more likely policy treatment: a mix of short run policies alongside a consistent plan to deal with medium-term challenges.

Moreover, the link between short run and medium-term outlooks still needs to be strengthened. Correct the drawbacks of the old regime such as organized corruption, weak infrastructure, injustice, oppression, and much more need the post- transitional government to make more and more efforts. Additionally, there is a great urge for a rational opposition that raises country's advantages over its own close gains besides forbearing people to overcome the transitional period hurdles safely.

\section{References}

Abouleinein, S., El-Laithy, H., and Kheir-El-Din, H., (2009) "The impact of phasing out subsidies of petroleum energy products in Egypt" The Egyptian Center for Economic Studies, 145, 1:44

Central Agency for Population Mobilization and Statistics (CAPMAS): Monthly Statistical Bulletin, several Issues (2011:2013).

Central Bank of Egypt (CBE): Monthly Statistical Bulletin, several Issues.

Dabrowski, M., (2011) "Egypt: Political Transition vs. Economic Challenges?" Center for Social and Economic 23 Research (CASE), 7, available at 
www.case-research.eu.

Galal, A., (2011) "Egypt Post January 2011: An Economic Perspective," Economic Research Forum, 3, available at www.erf.org.eg/CMS/uploads/pdf/PP3.pdf.

Kandil, M., (2011) "Egyptian Economy Post January 25:Challenges and Prospects" The Egyptian Center for Economic Studies, 27, 1: 8.

Korotayev, A., and Zinkina, J., (2011) "Egyptian Revolution: A demographic Structural Analysis" Entelequia, 13, 1: 32 available at www.eumed.net/entelequia.

MENA Program: Egypt Dialogue Workshop Report, (2011) "Egypt's Economy in the Transitional Period" Chatham House, 1:13 available at www.chathamhouse.org.

Ministry of Finance: Government budgets, available at www.mof.gov.eg.

Ministry of Foreign Trade and Industry: International trade statistics \& Industrial Indicators, available at www.mfti.gov.eg.

Ministry of Planning and International Co-operation: Center for Project Evaluation and Macroeconomic Analysis, available at www.pema.gov.eg.

Ministry of Supply and Internal Trade: poverty Statistics, available www.msit.gov.eg.

Ministry of Tourism: Tourism Indicators, available at www.tourism.gov.eg.

United Nations Development Program, Egypt Human Development Report 2010: Youth in Egypt: Building our Future (United Nations Development Program and the Institute of National Planning, Egypt, 2010) available at www.undp.org.eg/Portals/0/NHDR\%202010\%20english.pdf.

World Bank /International Finance Corporation: Ease of Doing Business in Egypt, available at www.doingbusiness.org/data/exploreeconomies/egypt.

\section{Appendix}

\section{/2010: 2011/2012 ץ.. 9 Figure 1: Rate of Growth}

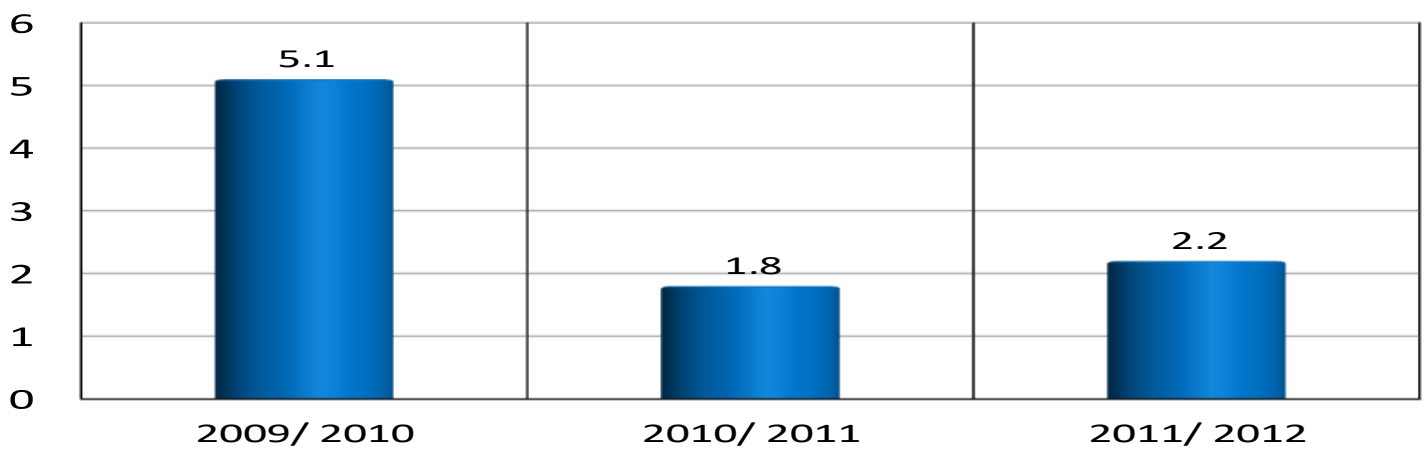

Figure 2:Rate of Growth (1st \& 2nd Quarters)(2011/2012 - 2012/2013 

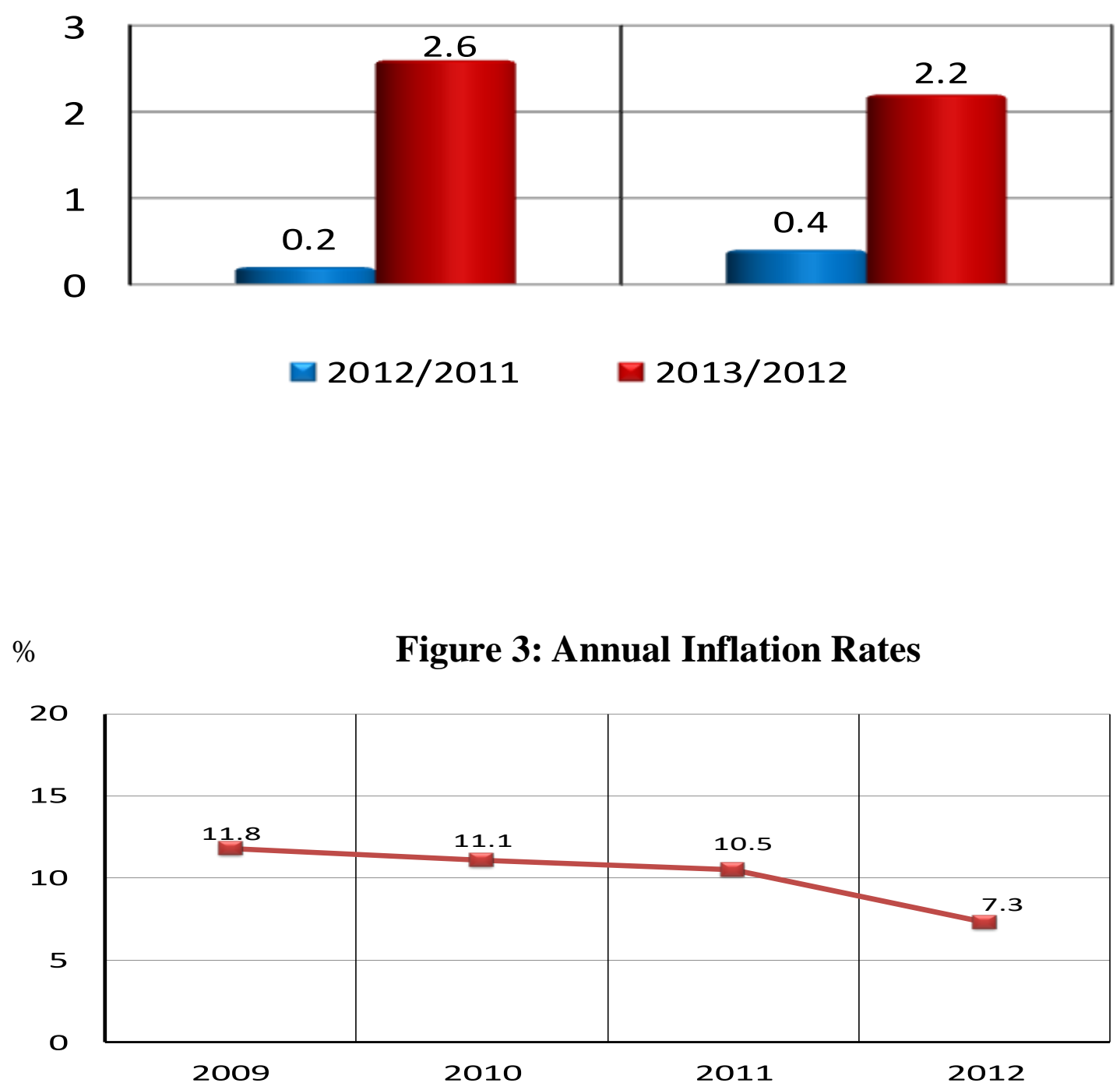

Figure 4: Inflation Rates (January- April 2012\&2013)

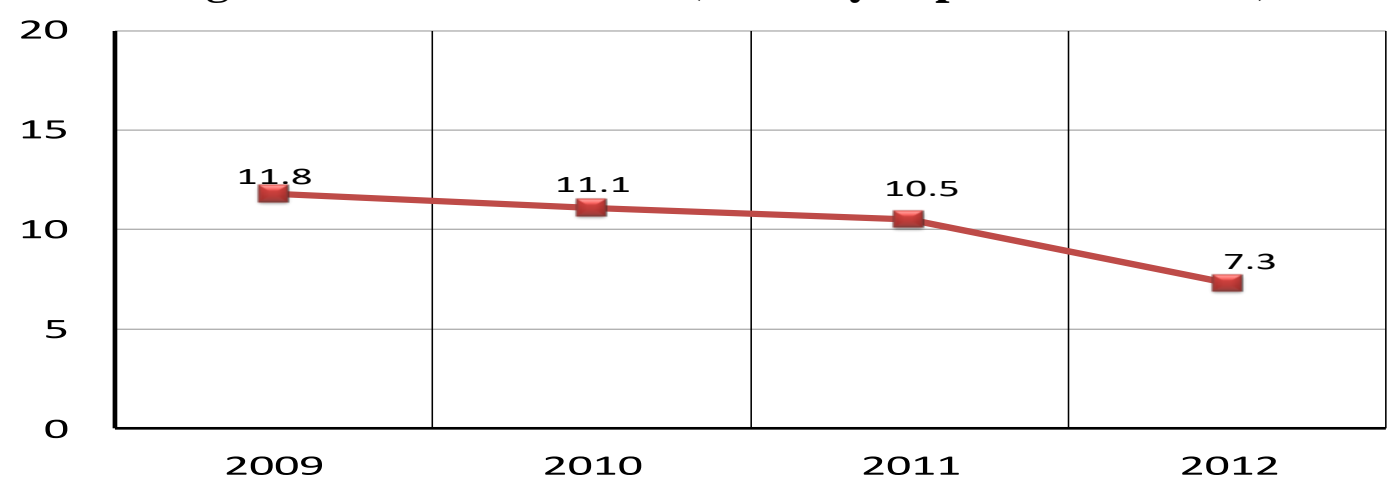

Figure 5: Number of Tourists 2009- 2012 (Million) 


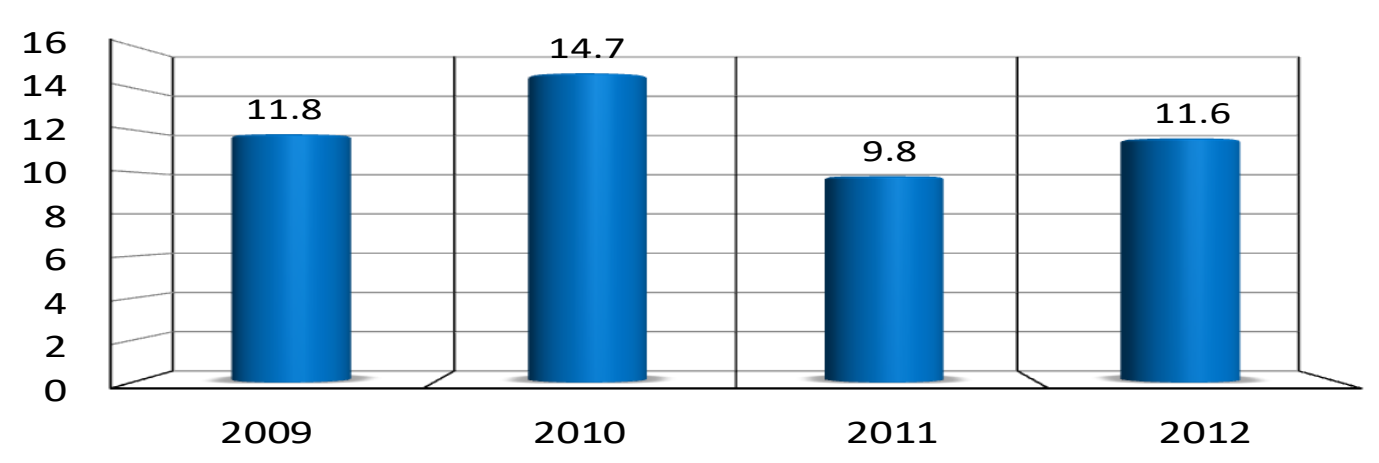

Figure 6: Number of tourists (January-March 2012\&2013) Thousand

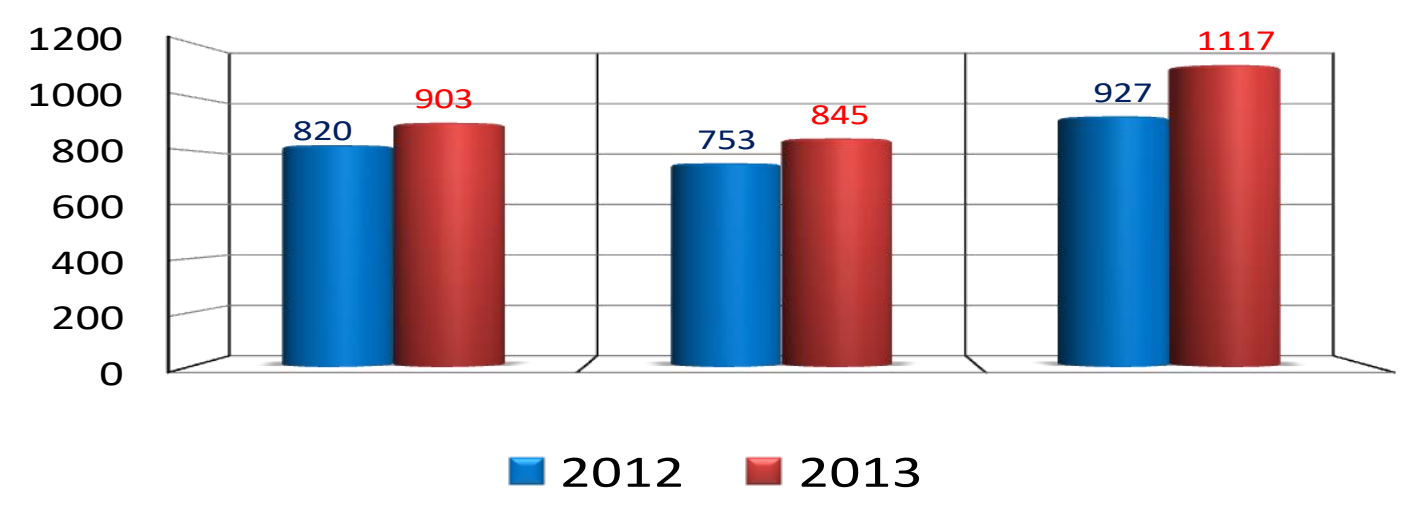

Figure7: Net International Reserves (June 2010- June 2012) \$ Billion

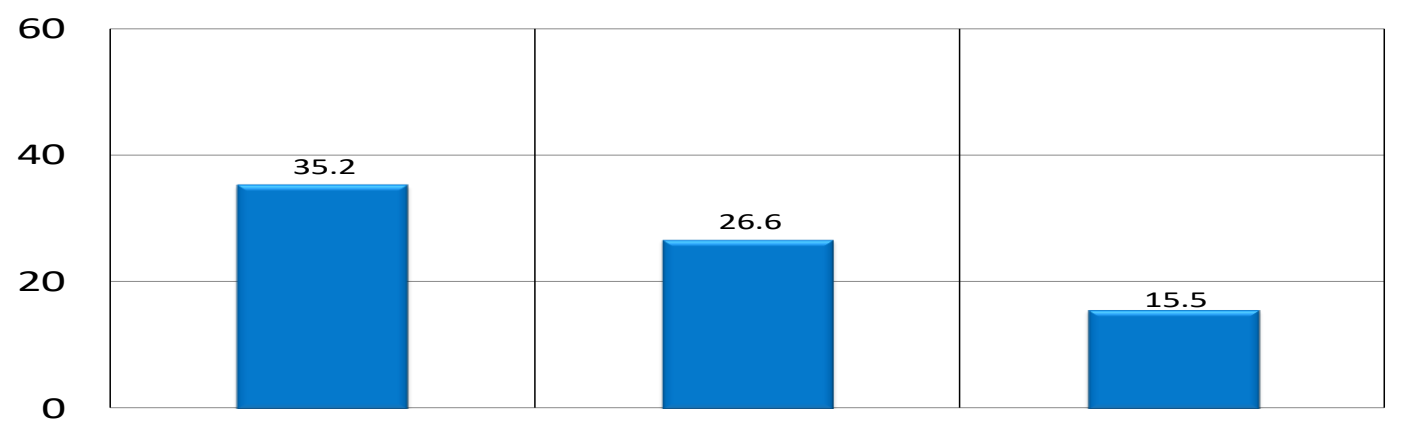

Figure8: Net International Reserves (January - May) \$ Billion

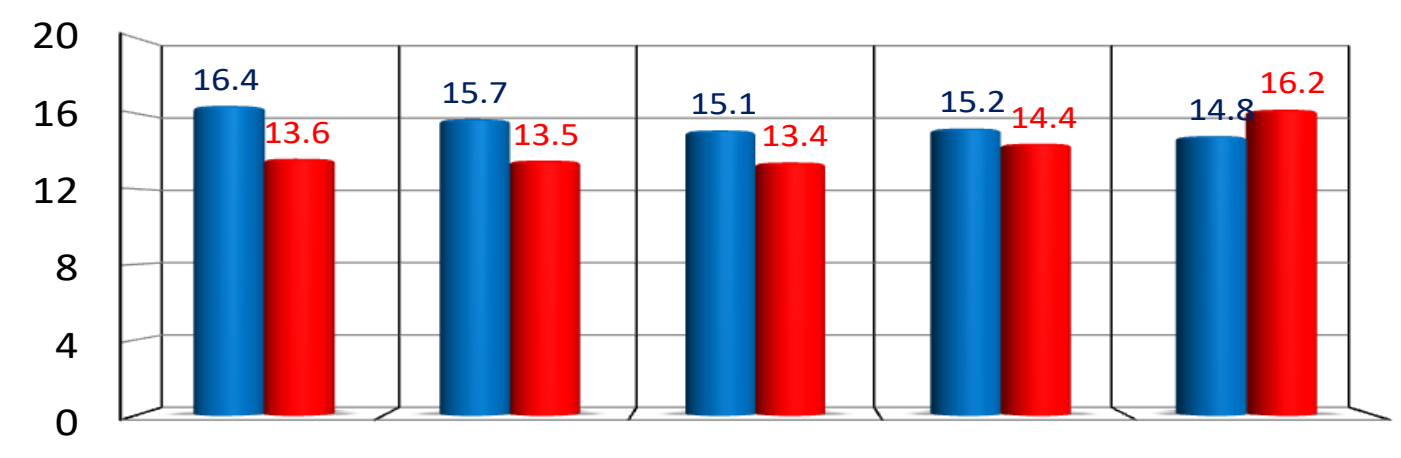
(日) 2012
일

Figure 9: Net FDI (July 2009- 


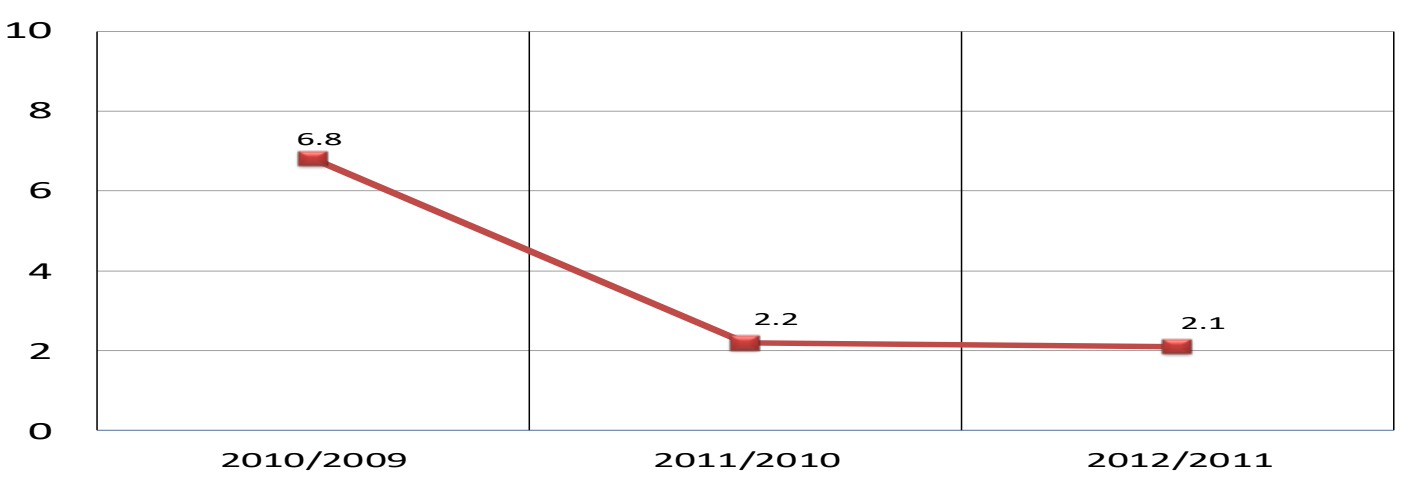

Figure 10: Net FDI (First \& second Quarters) \$ Billion

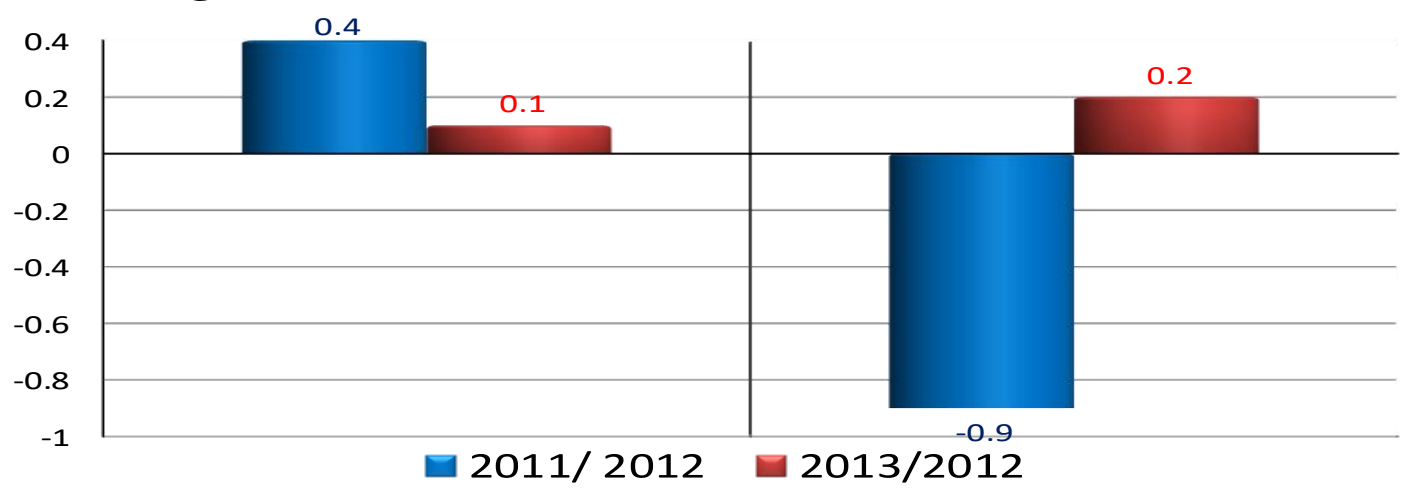

Figure 11: Egyptian Employees Remittances \$ Million

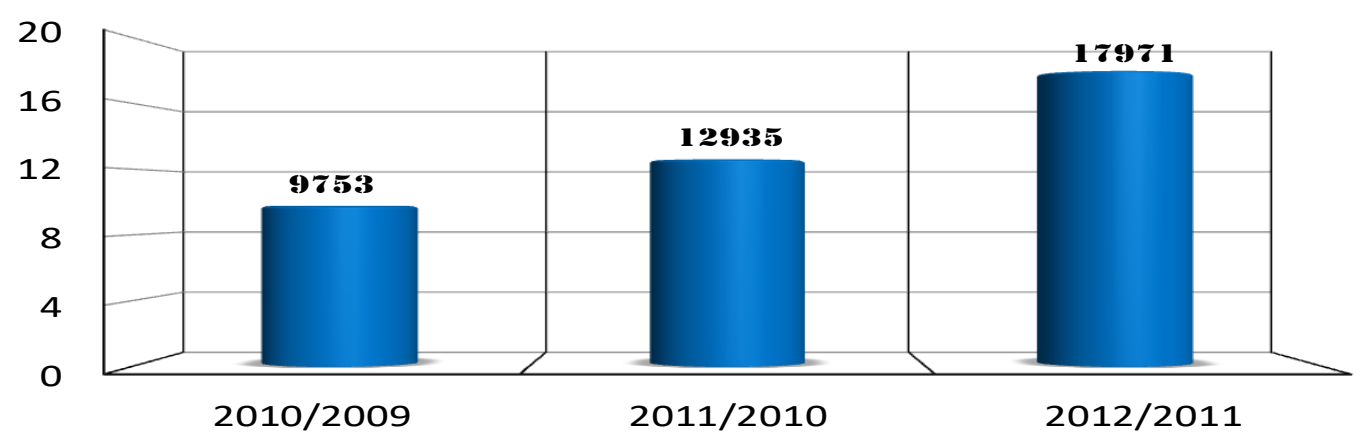

Figure 12: Egyptian Employees Remittances \$ Million

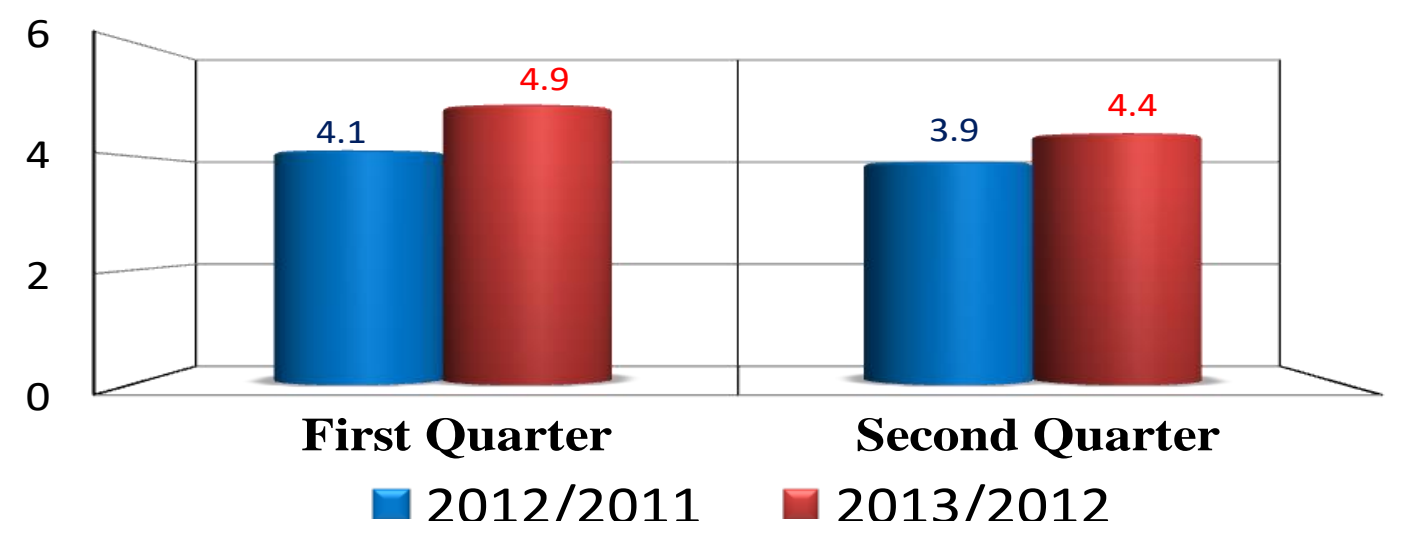

Figure 13: Suez Canal Revenues

\$ Million 


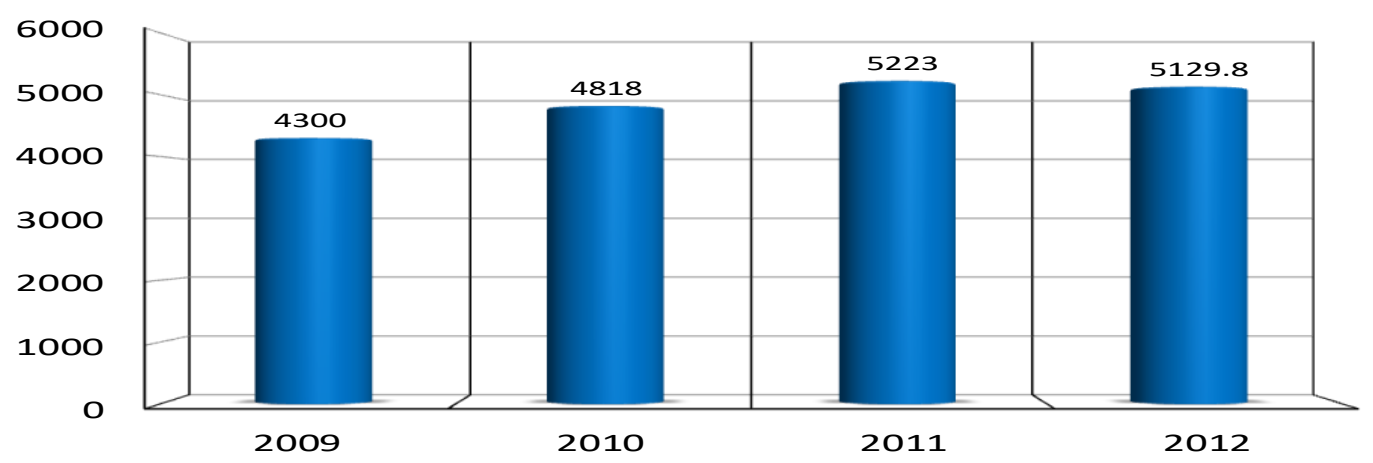

Figure 14: Suez Canal Revenues (January- March) \$ Million

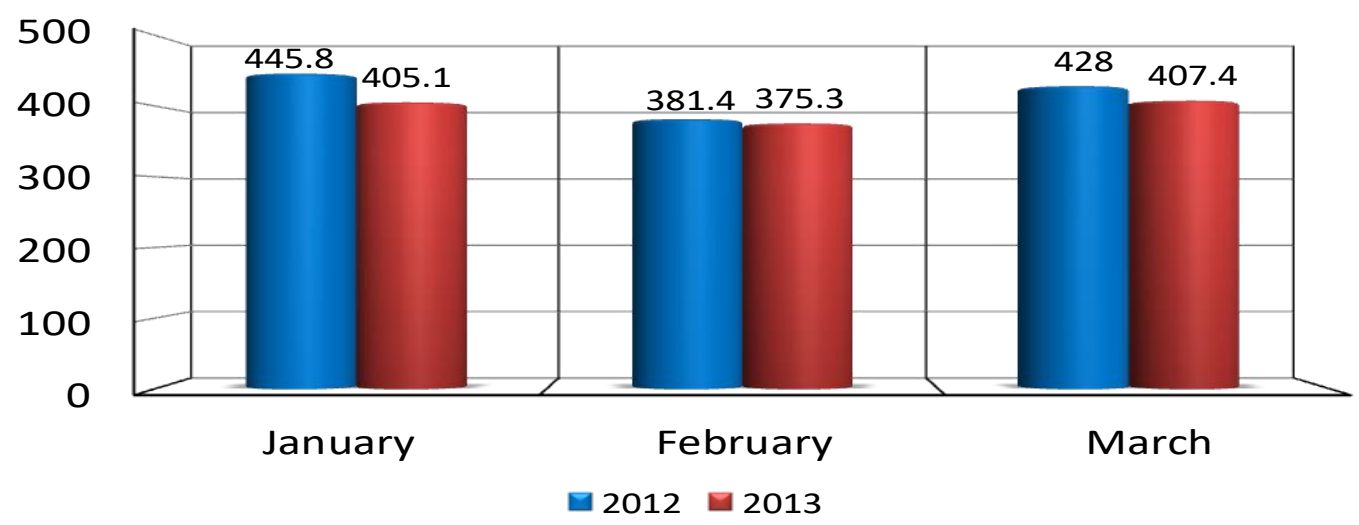

$\%$

Figure 15: unemployment Rates

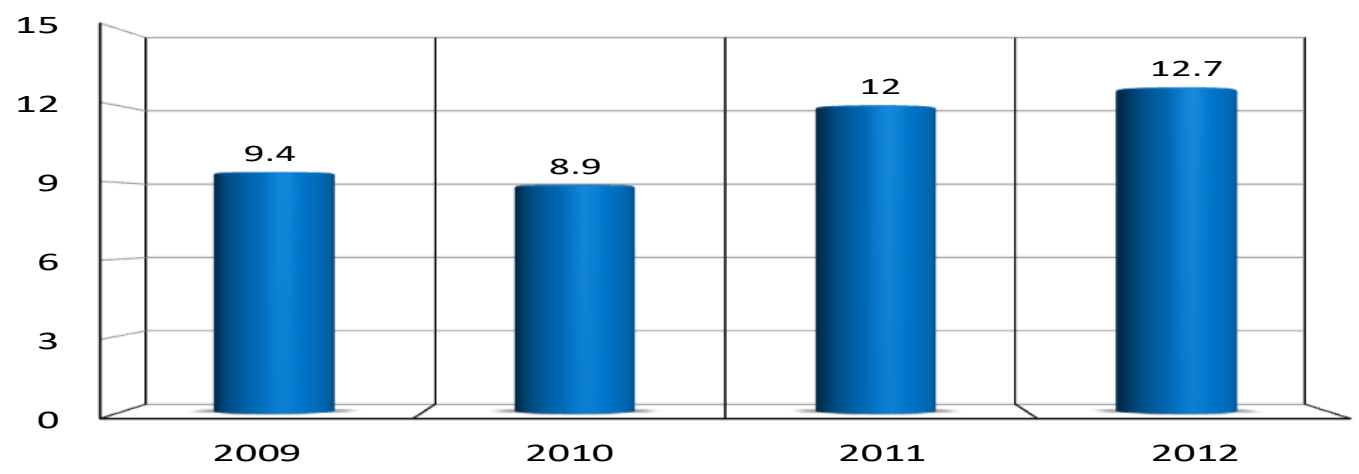

$\% \quad$ Figure 16: unemployment Rates (January- March)

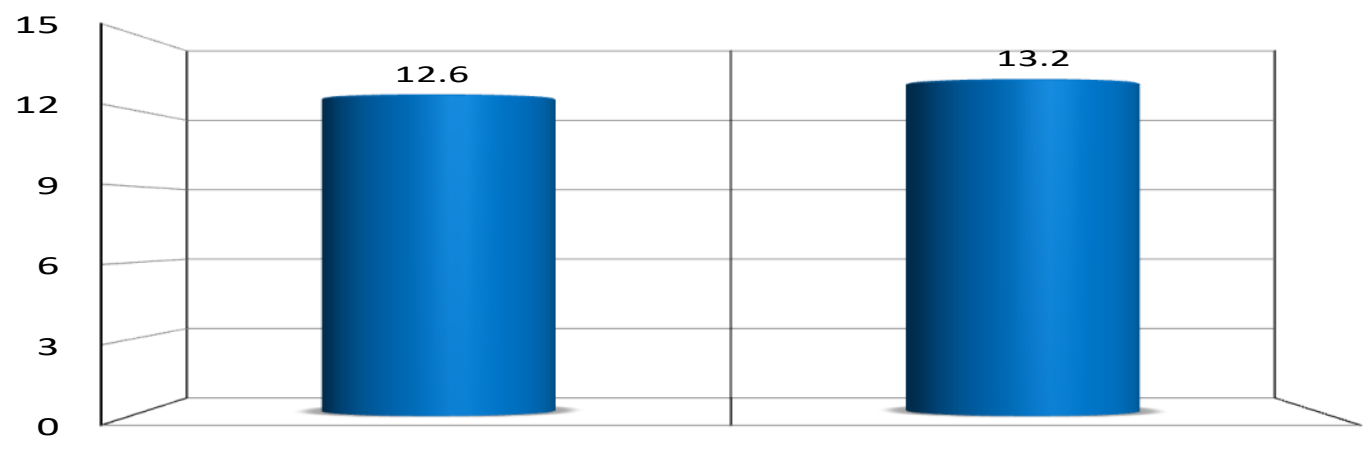

2012

2013

Figure17 Balance of Payment (2009- 2012) \$ Billion 


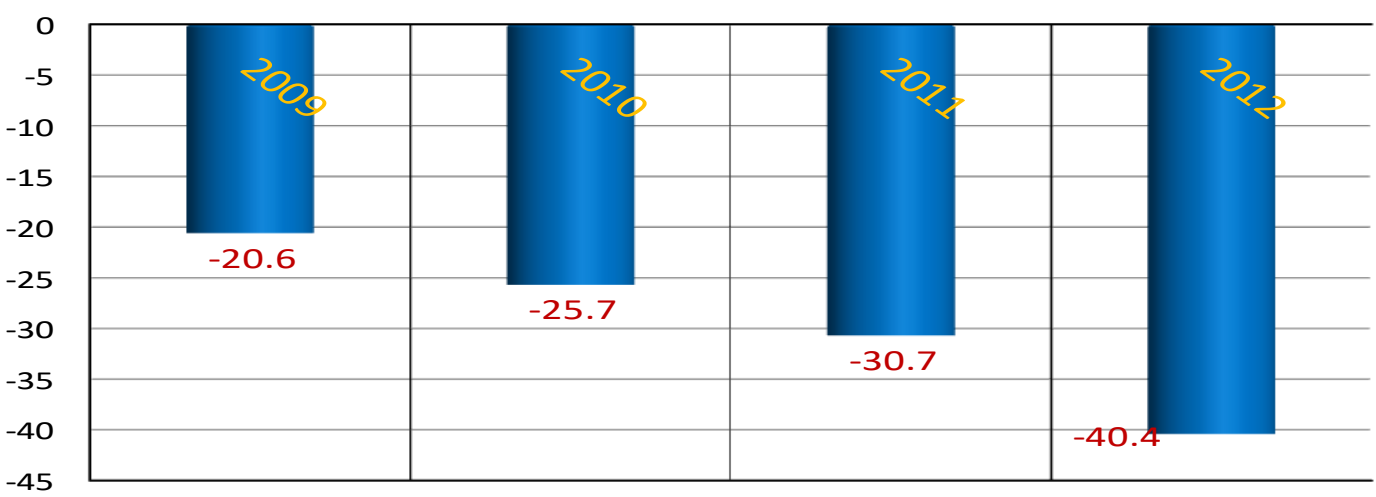

Figure18: Balance of Payment (January 2012- 2013) \$ Billion

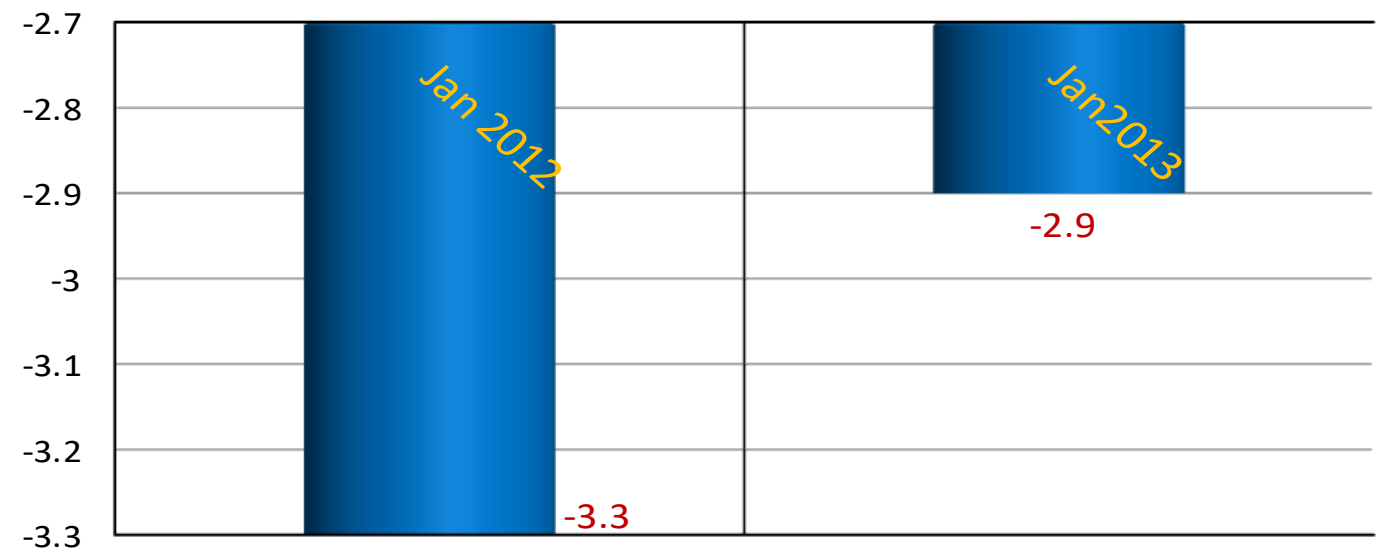

Figure19: Egyptian Exports \&Imports (2009- 2012) \$ Billion

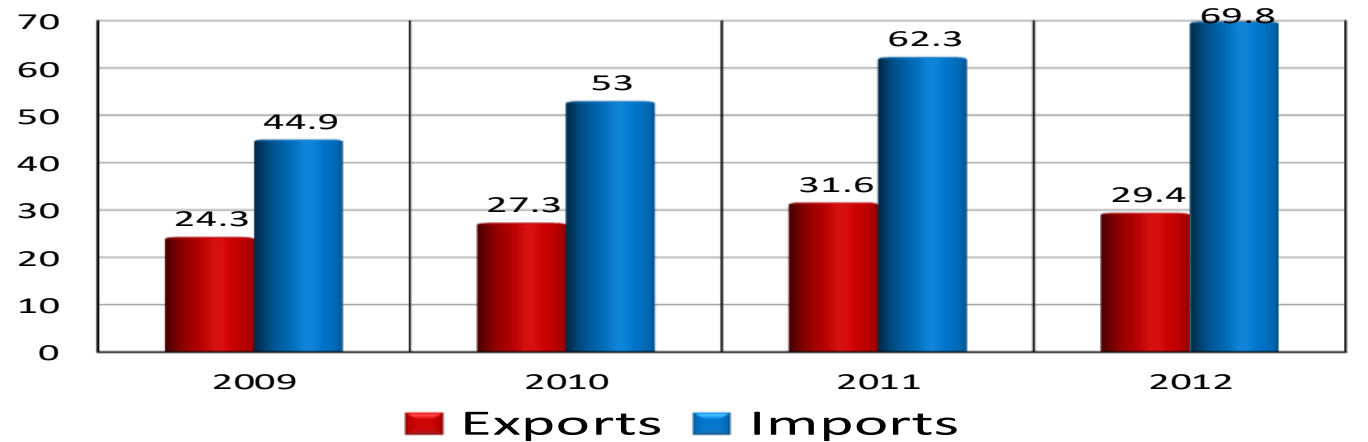

Figure20: Egyptian Exports \&Imports (January) \$ Billion

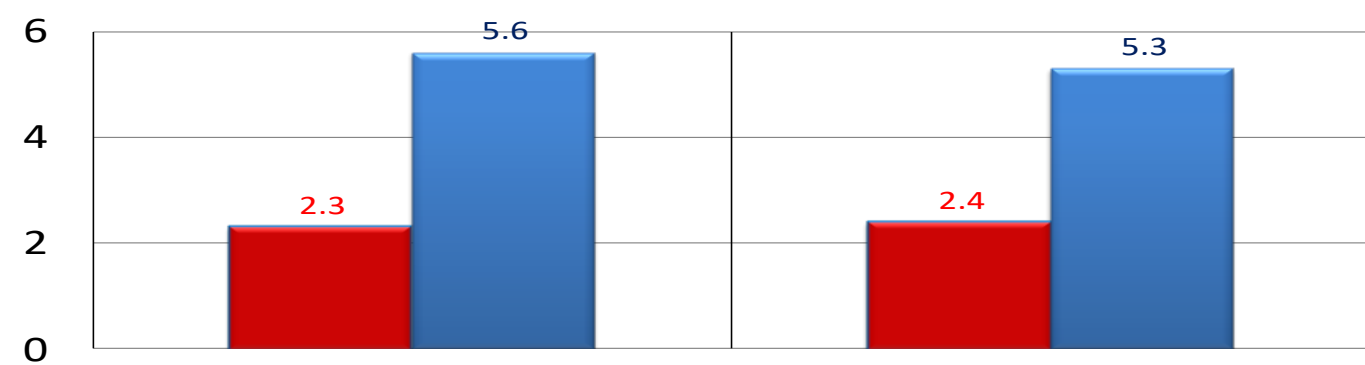

Exports $\square$ Imports

January 2012 January 2013

Figure 21: Poverty Rates 


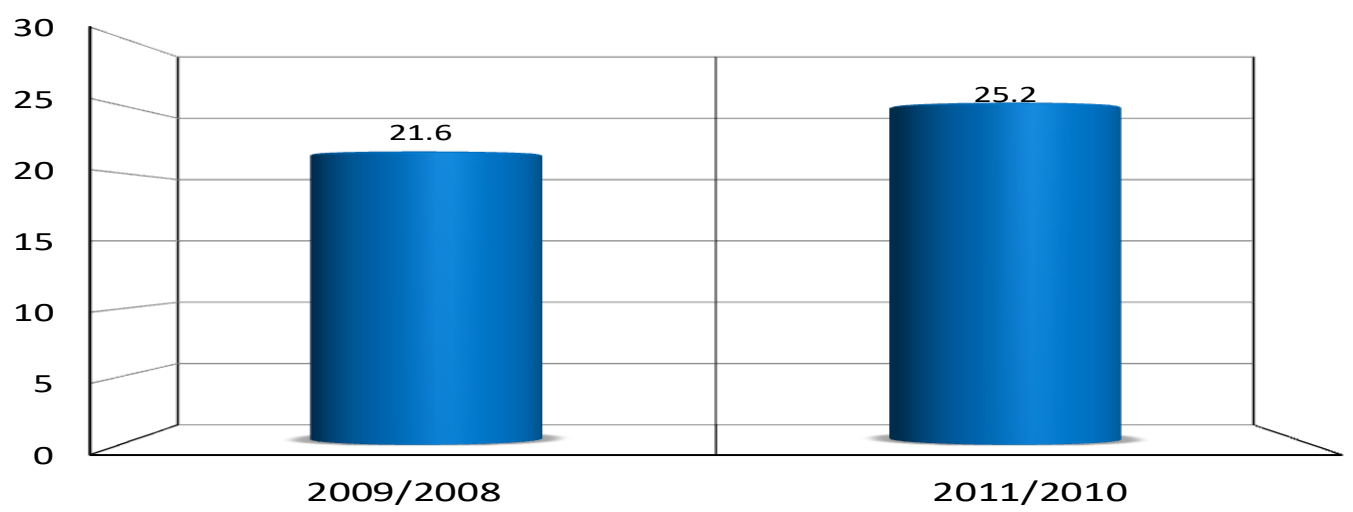

* It is calculated according to Income, expenditure, and consumption surveys every Two Years

Figure 22: Severe Poverty Rates

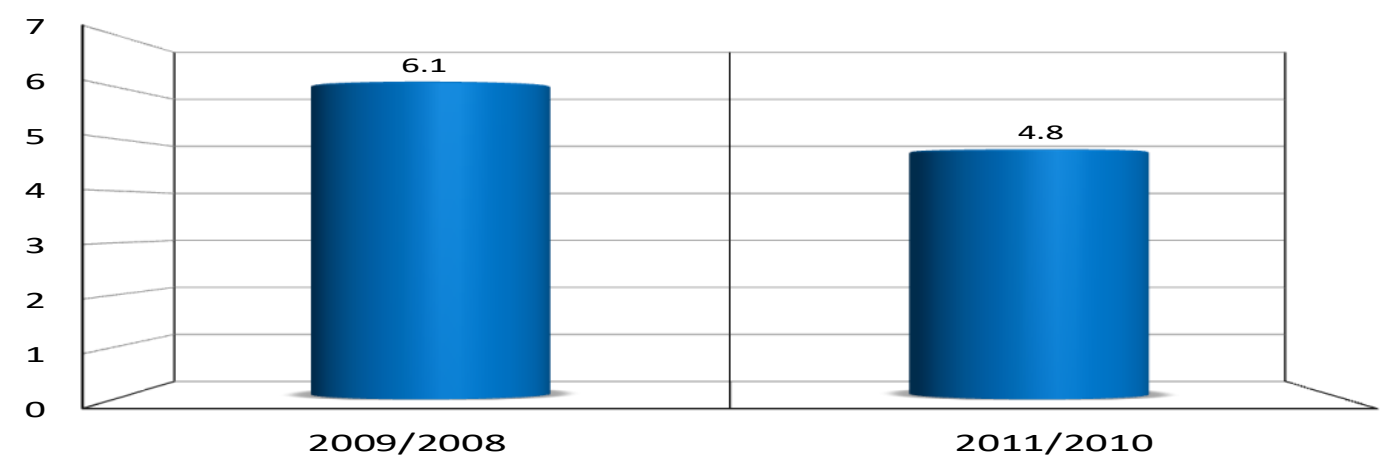

Figure 23: Poverty Rates for different country Regions

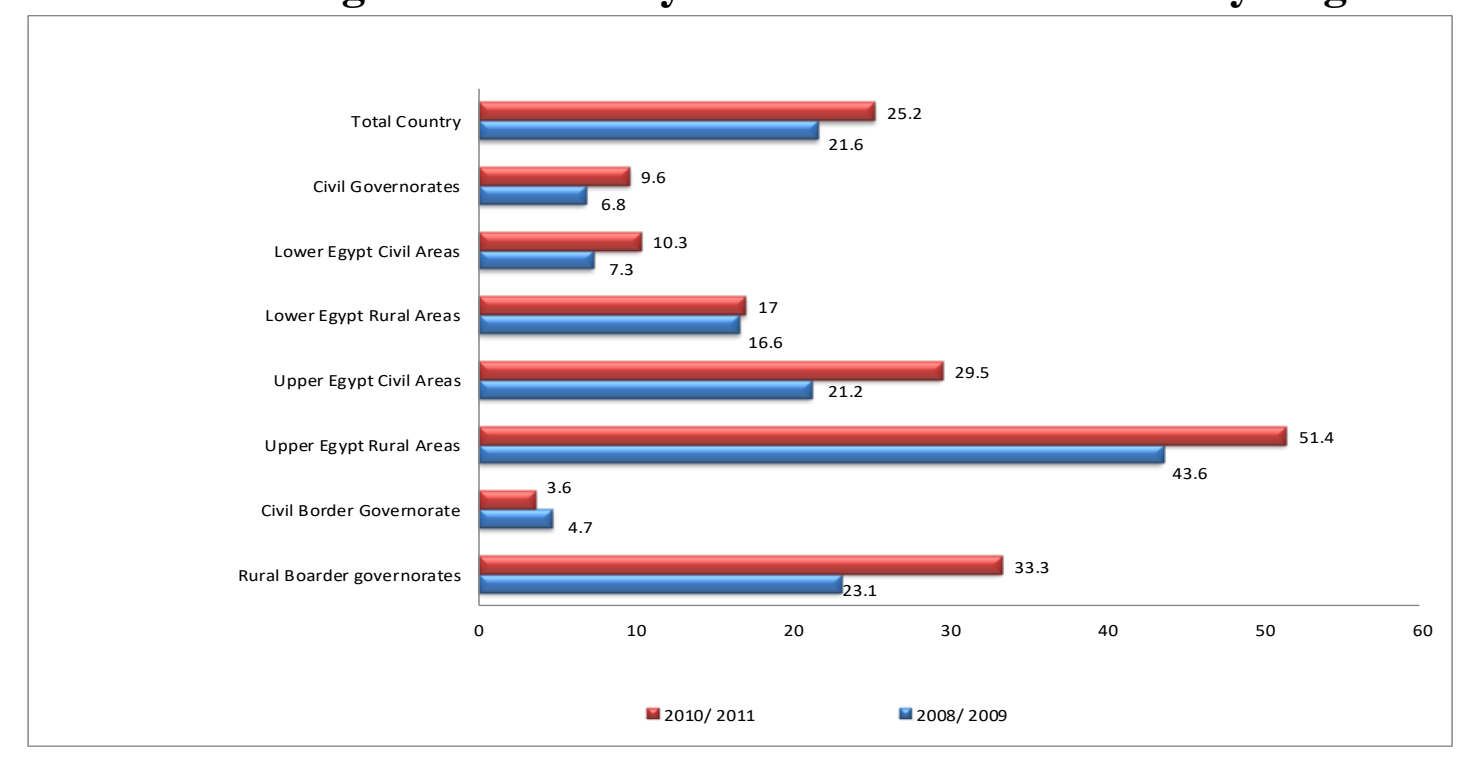

Figure 24: Total Subsides Billion Egyptian Pounds 


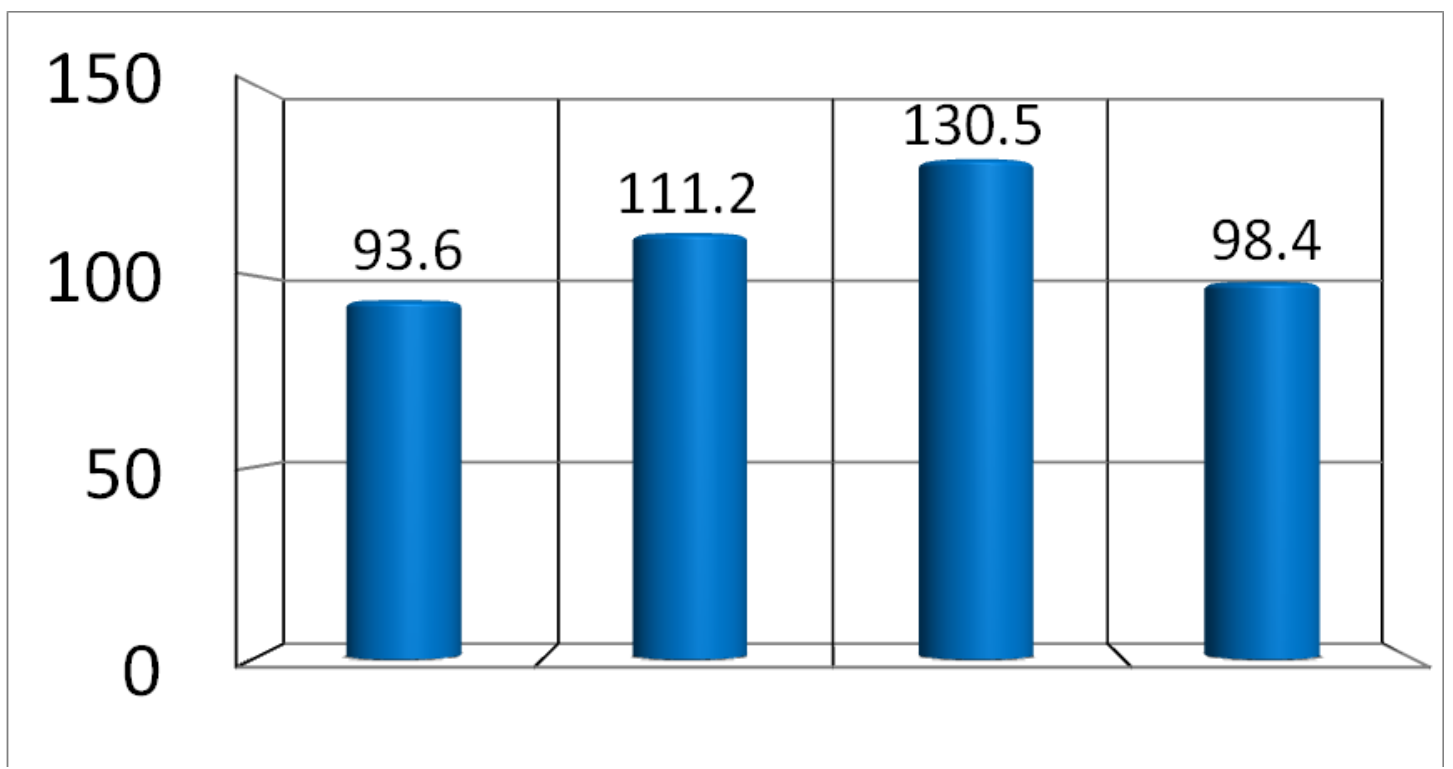

$2009 / 2010$

2010/11

$2011 / 12$

July12/ March2013

Figure 25: Total Subsides (July-March) Million Egyptian Pounds

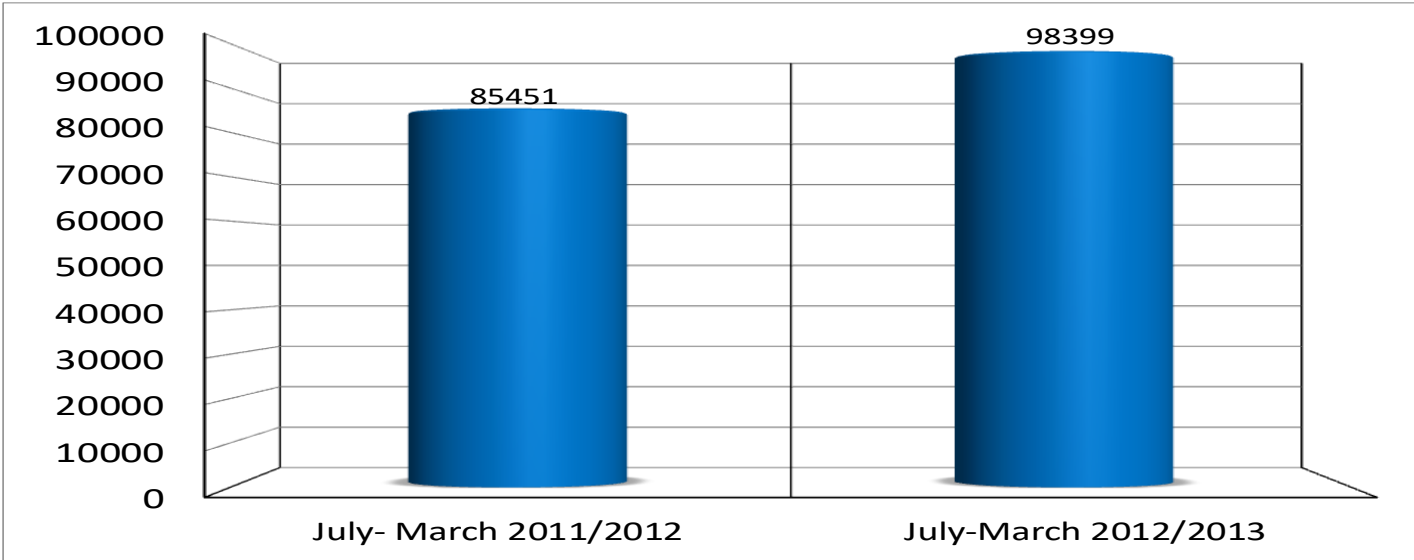

Figure 26: Credit Facilities Billion Egyptian Pounds

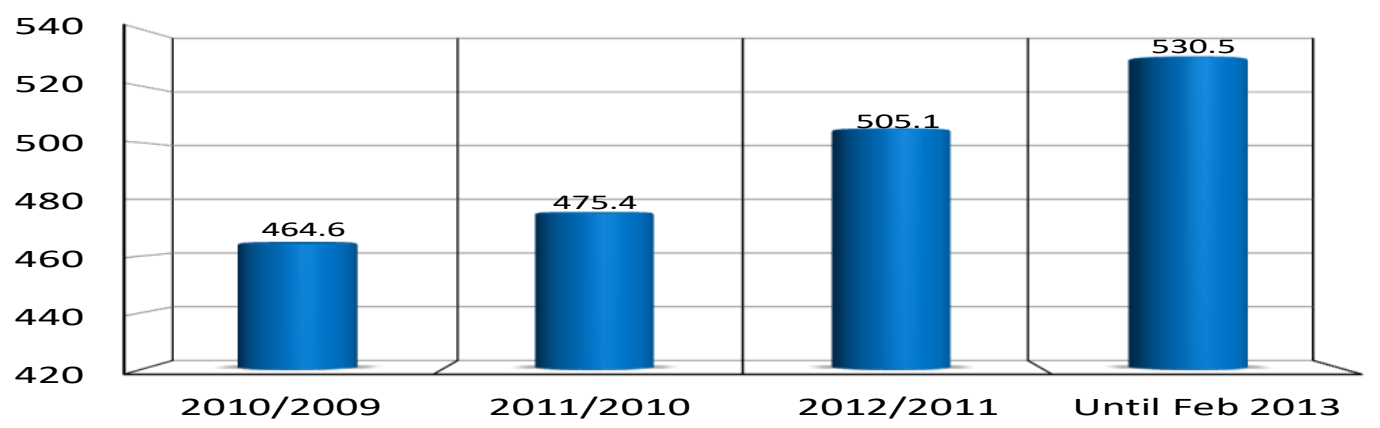

Figure 27: Total Population Inside Egypt (Thousands) 


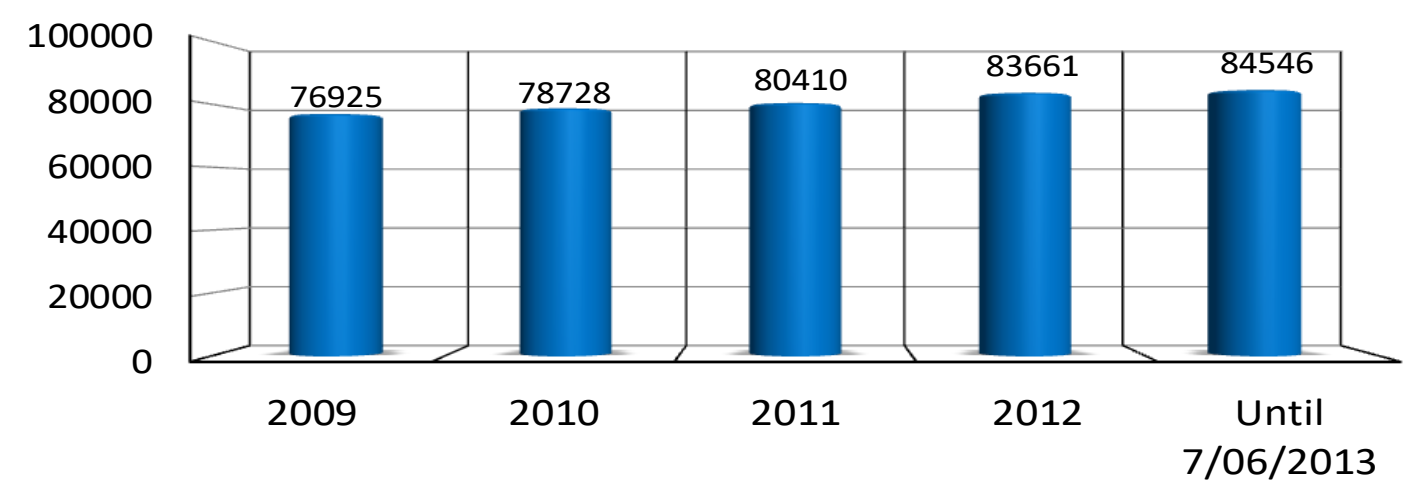

Figure 28:The Contribution of Economic Activities Per Sector To GDP

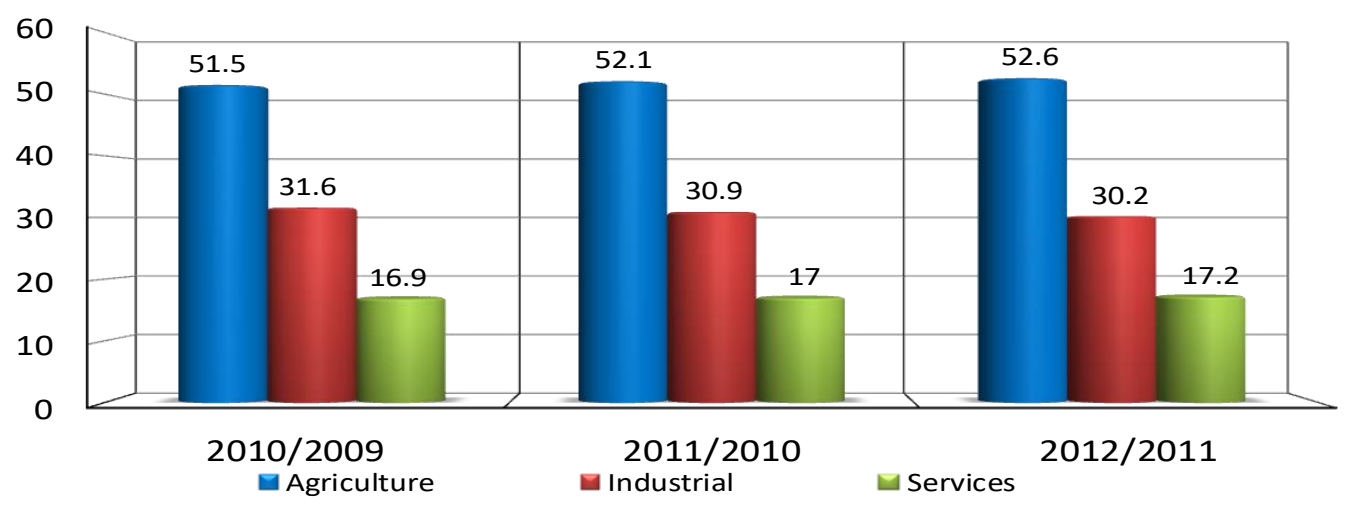

Figure 29: The Contribution of Economic Activities Per Sector To GDP $\left(1^{\text {st }} \& 2^{\text {nd }}\right.$ Quarters (2012/2013)

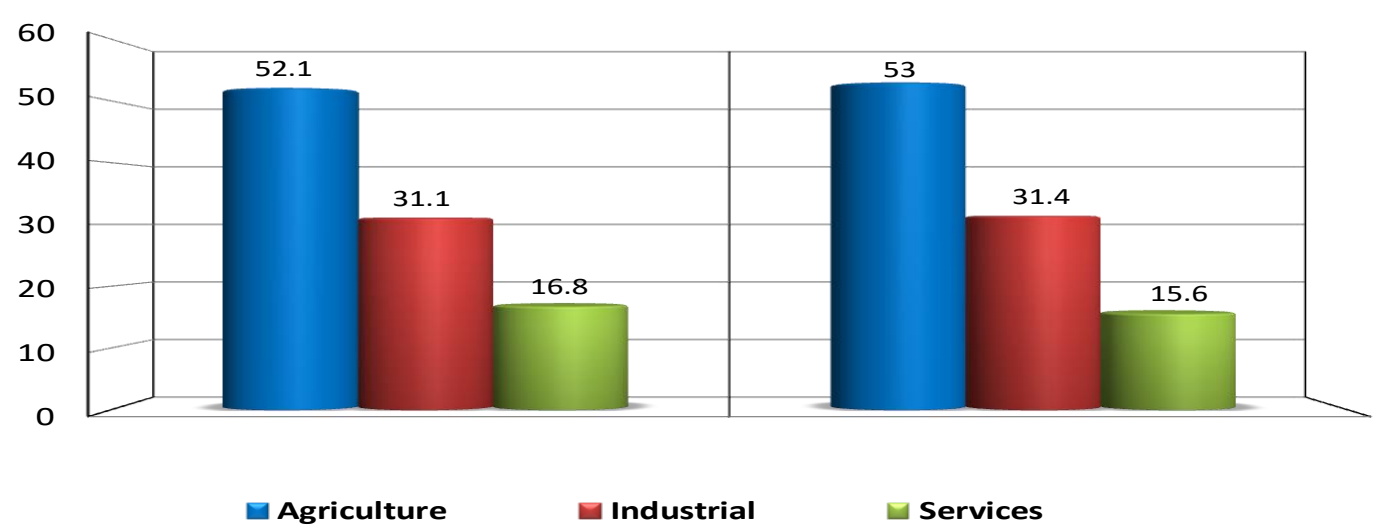

First Quarter

Second Quarter 